\title{
ANTIHYPERLIPIDEMIC AND HEPATOPROTECTIVE STUDIES ON LEAVES OF MACARANGA TANARIUS
}

\section{PHEBE HENDRA*, OKTARIANI AURELIA JAMIL, DIAN AYU MAHARANI, MARIA ANGELIKA SUHADI, CYNDI YULANDA PUTRI, FENTY, JEFFRY JULIANUS}

Department of Pharmacology and Toxicology, Faculty of Pharmacy, Sanata Dharma University, Jogjakarta, Indonesia. Email: phebe_hendra@usd.ac.id

Received: 04 September 2016, Revised and Accepted: 17 September 2016

\section{ABSTRACT}

Objective: This study investigated the antihyperlipidemic and hepatoprotective effects of the hexane-ethanol fraction of methanol extract of Macaranga tanarius (HEM) in rats.

Methods: The hexane-ethanol fraction was screened for toxicity by oral acute toxicity study. The antihyperlipidemic effect of the hexane-ethanol fraction and the unsolved of the hexane-ethanol fraction is measured against Wistar rats induced by glucose-fructose diets for 42 days through measuring serum cholesterol, triglyceride (TG), high-density lipoprotein cholesterol (HDL-c), low-density lipoprotein cholesterol (LDL-c), and fasting blood glucose. The hepatoprotective effect of the hexane-ethanol fraction is determined against Wistar rats with liver damage induced by carbon tetrachloride through measuring serum glutamate pyruvate transaminase (SGPT), serum glutamate oxaloacetate transaminase (SGOT), alkaline phosphatase (ALP), albumin, lactate dehydrogenase (LDH), and total bilirubin.

Results: There is no toxic effect that was observed on acute toxicity study. The TG, LDL-c, and fasting blood glucose levels were significantly (p<0.05) reduced after both of treatment the hexane-ethanol fraction and the unsolved HEM. Administration of the hexane-ethanol fraction 68.6 mg/kgBW significantly $(\mathrm{p}<0.05)$ prevented elevation of SGPT, SGOT, LDH, ALP, and decreasing of albumin level.

Conclusion: The study showed antihyperlipidemic and hepatoprotective activities of the HEM in animal models.

Keywords: Macaranga tanarius, Antihyperlipidemic, Hepatoprotective.

(C) 2017 The Authors. Published by Innovare Academic Sciences Pvt Ltd. This is an open access article under the CC BY license (http://creativecommons. org/licenses/by/4. 0/) DOI: http://dx.doi.org/10.22159/ajpcr.2017.v10i1.15044

\section{INTRODUCTION}

Nonalcoholic fatty liver disease (NAFLD) is defined as the presence of hepatic steatosis with no evidence of hepatocellular injury in the form of ballooning of the hepatocytes. NAFDL is associated with metabolic risk factors such as obesity, diabetes mellitus, and dyslipidemia [1] Global prevalence of NAFDL is $25.24 \%$, which was highest in the Middle East and South America and the lowest prevalence in Africa. Metabolic comorbidities associated with NAFDL included obesity, type 2 diabetes, hyperlipidemia, hypertension, and metabolic syndrome. As the global epidemic continues to fuel development of metabolic disorders, NAFDL will create a massive clinical and economic burden [2].

Carbon tetrachloride $\left(\mathrm{CCL}_{4}\right)$ is one of the most commonly hepatotoxic agents that have been reported to show steatosis, centrilobular necrosis, inflammation, fibrosis, and liver cancer in the experimental animals [3,4]. Administration of high carbohydrate diet in animal models is frequently induced obesity, insulin resistance, impaired glucose tolerance, hyperinsulinemia, hypertension, and hyperlipidemia [5-10].

Macaranga tanarius is a pioneer species in disturbed rainforest areas. It has great potential in scavenging free radical $[11,12]$ and can be a vital source of antioxidant phytochemicals [13]. Anti 2,2-diphenylpicrylhydrazyl radical-scavenging activity of the isolated compounds of M. tanarius also been reported previously [14-16]. These activities are effective in treating $\mathrm{CCL}_{4}$ induced toxicity.

The isolated ellagitannin and chebulagic acid of M. tanarius was found to inhibit $\alpha$-glucosidase and intestinal maltase that may benefit diabetes treatment [17]. Although the earlier study has demonstrated that the hexane-ethanol fraction of methanol extract of $M$. tanarius (HEM) for 5 days has not antidiabetic and antihyperlipidemic in rats feed with high glucose-fructose (GF) diet [10], a prolonged administration of
HEM remains to be established.

In this present study, the HEM was interesting to observe for their hepatoprotective and antihyperlipidemic anti-inflammatory activities. Carbon tetrachloride was chosen as model study for hepatotoxicity and administration of high GF to induce hyperlipidemia.

\section{METHODS}

\section{Plant material and chemicals}

The fresh leaves of M. tanarius were collected from Sleman, Yogyakarta, Indonesia and were identified and authenticated using descriptive literature. A voucher specimen was deposited in the Laboratory of Pharmaceutical Biology, Pharmacy Faculty, Sanata Dharma University, Yogyakarta, Indonesia. Sodium carboxymethyl cellulose (CMC) was supplied by Brataco Chemika, Indonesia. Glucose, fructose, methanol, and carbon tetrachloride as hepatotoxin were from E. Merck (Darmstadt, Germany). Olive oil was supplied by Bertolli, Italy. Diagnostic kit for the estimation of serum glutamate pyruvate transaminase (SGPT), serum glutamate oxaloacetate transaminase (SGOT), alkaline phosphatase (ALP), albumin, lactate dehydrogenase (LDH), total bilirubin, glucose, cholesterol, high-density lipoprotein cholesterol (HDL-c), low-density lipoprotein cholesterol (LDL-c), and triglyceride (TG) kits were purchased were from Roche Diagnostics $\mathrm{GmbH}$, Mannheim, Germany. All other chemicals were of analytical grade and were purchased from E. Merck, Darmstadt, Germany.

\section{Preparation of plant extract}

Dried leaves of M. tanarius were extracted with $50 \%$ aqueous methanol for $24 \mathrm{hrs}$ at room temperature. The crude extract was extracted with hexane-ethanol 50:50 for $24 \mathrm{hrs}$ at room temperature. The resulting suspension was filtered and was evaporated by vacuum rotary evaporator at $50^{\circ} \mathrm{C}$ to yield a solid residue of soluble HEM (yield 21\%) and unsoluble of HEM (UHEM) (yield 79\%). 
Test animals and housing

Adult male rats of Wistar strain weighing 150-250 g were selected for this experiment. The animals were obtained from the Imono Laboratory of Pharmacy Faculty of Sanata Dharma University, Indonesia. The animals were maintained under standard laboratory condition. They were housed in standard cages (five animals per cage) at temperature $22 \pm 2^{\circ} \mathrm{C}$ and $12: 12 \mathrm{hrs}$ light dark cycle. The animals were provided with pelleted diet as normal diet or GF-enriched diet and water ad libitum. The experimental protocol and procedures used in this study were approved with approval number KE/FK/551/EC/2016 by The Medical and Health Research Ethics Committee Faculty of Medicine Gadjah Mada University.

\section{Acute oral toxicity study}

Acute toxicity study was performed according to the acute toxic conventional method. Adult female rats of Wistar strain weighing 150-250 g were used for acute toxicity study. The animals were kept in fasting condition for overnight providing only water, and then, the HEM was administered orally at the doses of $34.2,342$, and $3420 \mathrm{mg} / \mathrm{kg} \mathrm{BW}$. The animals were closely observed for any signs of toxicity during the first $3 \mathrm{hrs}$, and the number of dead animals was recorded at $24 \mathrm{hrs}$.

\section{Antihyperlipidemic study}

Healthy rats were weighed and randomly divided into 4 groups of 5 animals in each. Group 1 as normal healthy control rats was fed normal diet for 52 days. Group 2-4 were fed GF diets for 42 days $[9,10]$. After 42 days, Group 2 were received CMC as negative control, whereas Group 3 were administered HEM $34.3 \mathrm{mg} / \mathrm{kgBW}$ and Group 4 were given UHEM $34.3 \mathrm{mg} / \mathrm{kgBW}$. All treatments were fed GF diet and continued for 10 days following oral administration. Blood for biochemical analysis from all groups was obtained by sinus orbitalis after $24 \mathrm{hrs}$ administration. The blood serum was used to measured serum cholesterol, TG, HDL-c, LDL-c, and fasting blood glucose. All tests were estimated in a Cobas C501 analyzer using commercial kits (Roche Diagnostic GmbH, Germany) following standard procedures.

\section{Hepatoprotective study}

Healthy rats were weighed and randomly divided into 5 groups of 5 animals in each. Group 1 were treated with carbon tetrachloride ( $2 \mathrm{ml} / \mathrm{kg}$, i.p.), in a 1:1 solution with olive oil [18,19]. Group 2 received olive oil $(2 \mathrm{ml} / \mathrm{kg}$, i.p) as negative control. Group 3-5 received HEM at doses $34.3,68.6$, and $134.1 \mathrm{mg} / \mathrm{kg}$ BW orally once and after $6 \mathrm{hrs}$, respectively, received treated carbon tetrachloride $(2 \mathrm{ml} / \mathrm{kg}$, i.p.). Blood sample from all groups was obtained by retro-orbital sampling after $24 \mathrm{hrs}$ application [19-22]. The blood serum was used to measured
SGPT, SGOT, ALP, albumin, LDH, and total bilirubin. All tests were estimated in a Cobas C501 analyzer using commercial kits (Roche Diagnostic GmbH, Germany) following standard procedures.

\section{Statistical analyses}

The results are expressed as mean \pm standard deviation. Data were analyzed using Kolmogorov-Smirnov test, followed by analysis of variance with $95 \%$ confidence interval. Scheffe test was used for significantly different results using the IBM SPSS 22 . Differences were regarded as statistically significant with $\mathrm{p}<0.05$

\section{RESULTS}

Acute toxicity study in rats indicated that oral administration of HEM produced no toxic effect. No unusual changes in behavior or in locomotor activity and no signs of intoxication were observed.

The administration of GF diet exhibited a significant $(p<0.05)$ rise in TG, LDL-c, and fasting blood glucose. This was significantly $(\mathrm{p}<0.05)$ reduced after both of treatment the HEM and the UHEM as shown in Table 1.

The effect of HEM on SGPT, SGOT, ALP, albumin, LDH, total bilirubin in $\mathrm{CCl}_{4}$ intoxicated rats was summarized in Table 2. The biomarker enzyme levels are mainly increased in the hepatic damage by the $\mathrm{CCl}_{4}$. SGPT, SGOT, LDH, ALP, and total bilirubin increased significantly $(p<0.05)$ and albumin decreased significantly $(p<0.05)$ with $\mathrm{CCl}$ treated. Administration of HEM $68.6 \mathrm{mg} / \mathrm{kgBW}$ significantly $(\mathrm{p}<0.05)$ prevented elevation of SGPT, SGOT, LDH, ALP, and decreasing of albumin level, thus signifying its hepatoprotective effect.

\section{DISCUSSION}

For the acute toxicity study, the results suggest that the HEM is not toxic after an acute expose to the dose of $3420 \mathrm{mg} / \mathrm{kg}$.

After 42 days of GF diet, the elevation of TG, LDL-c, and fasting blood glucose levels were recorded in this study indicated that GF diet caused hyperlipidemia and hyperglycemia in rats. Our previous study demonstrated that the HEM for 5 days has not antidiabetic and antihyperlipidemic in rats feed with high GF diet [10]. However, in this study, concurrent administration 10 days both of HEM markedly decreased the release of TG, LDL-c, and fasting blood glucose levels. This indicates that the prolonged administration of fraction possesses an antihyperlipidemic and antihyperglycemic effect against GF diet.

Table 1: Effect of HEM on lipid parameters and fasting blood glucose in rats feeds with GF diets

\begin{tabular}{|c|c|c|c|c|c|}
\hline Treatment & Cholesterol (mmol/l) & Triglyceride (mmol/l) & HDL-c (mmol/l) & LDL-c (mmol/l) & $\begin{array}{l}\text { Fasting blood } \\
\text { glucose }(\mathrm{mmol} / \mathrm{l})\end{array}$ \\
\hline Normal diet & $1.70 \pm 0.14$ & $0.87 \pm 0.10^{\mathrm{b}}$ & $0.81 \pm 0.02^{\mathrm{b}}$ & $0.23 \pm 0.01^{\mathrm{b}}$ & $3.21 \pm 0.16^{b}$ \\
\hline GF & $1.88 \pm 0.15$ & $2.98 \pm 0.25^{\mathrm{a}}$ & $0.65 \pm 0.05^{\mathrm{a}}$ & $0.33 \pm 0.04^{\mathrm{a}}$ & $4.97 \pm 0.29^{a}$ \\
\hline GF+HEM $34.3 \mathrm{mg} / \mathrm{kgBW}$ & $1.81 \pm 0.19$ & $1.25 \pm 0.49^{b}$ & $0.80 \pm 0.08^{\mathrm{b}}$ & $0.25 \pm 0.03^{b}$ & $3.81 \pm 0.61^{b}$ \\
\hline GF+UHEM $34.3 \mathrm{mg} / \mathrm{kgBW}$ & $1.92 \pm 0.13$ & $2.12 \pm 0.14^{\mathrm{a}, \mathrm{b}}$ & $0.76 \pm 0.03^{b}$ & $0.25 \pm 0.01^{b}$ & $3.83 \pm 0.26^{\mathrm{a}, \mathrm{b}}$ \\
\hline
\end{tabular}

Values are expressed as mean \pm SD of five animals in each group; ${ }^{a} p<0.05$ vs normal diet; ${ }^{b} p<0.05$ vs GF. GF: Glucose-fructose, HDL-c: High-density lipoprotein cholesterol, LDL-c: Low-density lipoprotein cholesterol, HEM: Hexane-ethanol fraction of methanol extract of Macaranga tanarius, UHEM: Unsoluble of hexane-ethanol fraction of methanol extract of Macaranga tanarius, SD: Standard deviation

Table 2: Effect of HEM on different biochemical parameters in carbon tetrachloride-induced hepatotoxicity

\begin{tabular}{|c|c|c|c|c|c|c|}
\hline Treatment & SGPT (U/l) & SGOT (U/1) & Albumin (mg/dl) & LDH (U/l) & $\operatorname{ALP}(U / \mathbf{l})$ & Total Bilirubin (mg/dl) \\
\hline Normal & $55.3 \pm 4.4^{\mathrm{b}}$ & $144.0 \pm 6.5^{\mathrm{b}}$ & $3.47 \pm 0.15^{b}$ & $1021.2 \pm 277.0^{\mathrm{b}}$ & $177.8 \pm 29.0^{\mathrm{b}}$ & $0.16 \pm 0.01^{b}$ \\
\hline Standard $\mathrm{CCl}_{4}$ & $156.1 \pm 16.9^{a}$ & $674.3 \pm 12.0^{\mathrm{a}}$ & $2.85 \pm 0,12^{\mathrm{a}}$ & $1848.8 \pm 106.85^{\mathrm{a}}$ & $244.4 \pm 30.6^{a}$ & $0.22 \pm 0.05^{\mathrm{a}}$ \\
\hline HEM $34.3 \mathrm{mg} / \mathrm{kgBW}$ & $72.2 \pm 10.0^{\mathrm{b}}$ & $510.4 \pm 176.7^{a}$ & $3.39 \pm 0.10^{\mathrm{b}}$ & $968.4 \pm 119.0^{\mathrm{b}}$ & $150.8 \pm 18.2^{\mathrm{b}}$ & $0.22 \pm 0.06^{\mathrm{a}}$ \\
\hline HEM 68.6 mg/kgBW & $57.3 \pm 10.7^{\mathrm{b}}$ & $170.0 \pm 39.1^{\mathrm{b}}$ & $3.27 \pm 0.09^{\mathrm{a}, \mathrm{b}}$ & $875.0 \pm 43.3^{\mathrm{b}}$ & $183.0 \pm 12.1^{b}$ & $0.21 \pm 0.02^{\mathrm{a}}$ \\
\hline HEM $137.1 \mathrm{mg} / \mathrm{kgBW}$ & $157.4 \pm 20.3^{a}$ & $639.4 \pm 35.6^{a}$ & $3.09 \pm 0,11^{\mathrm{a}, \mathrm{b}}$ & $835.8 \pm 54.0^{\mathrm{b}}$ & $199.6 \pm 21.5^{b}$ & $0.24 \pm 0.02^{\mathrm{a}}$ \\
\hline
\end{tabular}

Values are expressed as mean \pm SD of five animals in each group; ${ }^{a} \mathrm{p}<0.05$ vs normal diet; ${ }^{b} \mathrm{p}<0.05$ vs standard. SGPT: Serum glutamate pyruvate transaminase, SGOT: Serum glutamate oxaloacetate transaminase, LDH: Lactate dehydrogenase, ALP: Alkaline phosphatase, HEM: Hexane-ethanol fraction of methanol extract of Macaranga tanarius, SD: Standard deviation 
Puteri and Kawabat, 2010, have investigated the $\alpha$-glucosidase inhibitor activity of isolated of $M$. tanarius [17]. It is reasonable to suppose the antihyperlipidemic and antihyperglycemic effect of HEM. Similarly, we have shown that the UHEM showed a reduction in TG, LDL-c, and fasting blood glucose levels. In contrast, it can be postulated that the UHEM contained pharmacologically active compound(s) that interfere with the elevation TG, LDL-c, and fasting blood glucose levels.

In this present study, we examined the hepatoprotective effect of HEM against liver damage induced by carbon tetrachloride in rats Carbon tetrachloride as common hepatotoxin used in the experimental study, induced a significant elevation of blood hydroperoxide and malondialdehyde (lipid peroxidation products in liver, moreover, this toxicant caused a significant decrease in glutathione content in hepatic tissue [23]. Carbon tetrachloride exhibited drastic alterations on liver such as extensive fatty change, fatty degeneration [24], and infiltration by inflammatory cells [25]. Administration of carbon tetrachloride causes severe liver injuries in the present rats. Our results provided evidence for the hepatotoxicity effect of carbon tetrachloride $(2 \mathrm{ml} / \mathrm{kg})$ on the liver functions (Table 2). The SGPT, SGOT, ALP, LDH, albumin, and total bilirubin level significantly increased when compared with the normal rats $[4,26,27]$. This injury is indicated of liver cell damage as steatosis and leakage of enzymes from cell $[18,22,28]$.

The result of this study shows that the HEM has the potential to protect the hepatotoxicity. Since the HEM contains antioxidant compound [11-16], it might effective in treating $\mathrm{CCl}_{4}$-induced hepatotoxicity. It results the HEM at dose of $68.6 \mathrm{mg} / \mathrm{kgBW}$ gave the most potent hepatoprotective effect which decreased the elevation of SGPT, SGOT, LDH, ALP, and increasing of albumin level. The possible mechanism of action may be associated with scavenging of free radicals for $\mathrm{CCl}_{4}$ toxicity.

\section{CONCLUSION}

In conclusion, the study showed antihyperlipidemic and hepatoprotective activities of HEM in animal modes.

\section{ACKNOWLEDGMENT}

This research project was supported by a grant from Ministry of Research, Technology and Higher Education of the Republic of Indonesia with contract number 010/HB-LIT/III.2016.

\section{REFERENCES}

1. Chalasani N, Younossi Z, Lavine JE, Diehl AM, Brunt EM, Cusi K, et al. The diagnosis and management of non-alcoholic fatty liver disease: Practice guideline by the American association for the study of liver diseases, American college of gastroenterology, and the American gastroenterological association. Hepatology 2012;55(6):2005-23.

2. Younossi ZM, Koenig AB, Abdelatif D, Fazel Y, Henry L, Wymer M, et al. Global epidemiology of nonalcoholic fatty liver disease-meta-analytic assessment of prevalence, incidence, and outcomes. Hepatology 2016;64(1):73-84.

3. Riordan JD, Nadeau JH. Modeling progressive non-alcoholic fatty liver disease in the laboratory mouse. Mamm Genome 2014;25(9-10):473-86

4. Jonnalagadda VG, Selkar NA, Vemula SK, Chawda MB, Thakur KS, Vahalia MK, et al. Abrogation of carbon tetrachloride (CCL4) induced hepatotoxicity by arogyavardhani in Wistar rats. Asian J Pharm Clin Res 2014;7(1):183-5.

5. Elliott SS, Keim NL, Stern JS, Teff K, Havel PJ. Fructose, weight gain, and the insulin resistance syndrome. Am J Clin Nutr 2002;76(5):911-22.

6. Nugroho AE. Review: Animal model of diabetes mellitus: Pathology and mechanism of some diabetogenics. Biodiversitas 2006;7(7):378-82 (in Indonesian).

7. Saleh DO, El-Awdan SA, Nofel SM, El-Eraky WI, El-Khatib AS, Kenawy SA. Estrogens improve the cardiovascular alterations in fructose-induced insulin resistant ovariactoized rats. Int J Pharm Pharm
Sci 2015;7(7):241-7.

8. Srivastava SP, Mishra A, Lakshmi V, Tamrakar AK, Srivastava MN, Srivastava AK. Antidiabetic and antidyslipemic activity of ethyl acetate fractions of xylocarpus granatum and xylocarpus molluccensis on high fructose high fat and high sucrose hig fat fed-low dosed streptozotocin treated diabetic rats. Int J Pharm Pharm Sci 2015;7(2):537-43.

9. Aligita W, Kurniati NF, Sukandar EY. Antidiabetic study of combination of Andrographis paniculata (Burm. F.) Wallich. Ex Ness. Herbs extract and Guazuma ulmifolia Lamk. Leaves extract in obese diabetic mice model. Int J Pharm Pharm Sci 2016;8(1):316-20.

10. Hendra P, Fenty, Julianus J. Evaluation of antidiabetic and antihuperlidemic activities of Macaranga tanarius in rats feed with high glucose-fructose diet. Int J Pharm Pharm Sci 2016;8(1):462-3.

11. Kumazawa S, Nakamura J, Murase M, Miyagawa M, Ahn MR, Fukumoto S. Plant origin of okinawan propolis: Honeybee behavior observation and phytochemical analysis. Naturwissenschaften 2008;95(8):781-6.

12. Lim TY, Lim YY, Yule CM. Evaluation of antioxidant and anti-tyrosinase activities of four Macaranga species. Food Chem 2009;114:594-9.

13. Po-Chuen S, Govindasamy A, Daih-Huang K. Evaluation of antioxidant polyphenols in Taiwan's medicinal plants. Asian J Chem 2009;21(7):5556-62.

14. Phommart S, Sutthivaiyakit P, Chimnoi N, Ruchirawat R, Sutthivaiyakit S. Constituents of the leaves of Macaranga tanarius. J Nat Prod 2005;68(6):927-30.

15. Matsunami K, Takamori I, Shinzato T, Aramoto M, Kondo K, Otsuka $\mathrm{H}$, et al. Radical-scavenging activities of new megastigmane glucosides from Macaranga tanarius (L.) MÜLL.-ARG. Chem Pharm Bull (Tokyo) 2006;54(10):1403-7.

16. Matsunami K, Otsuka H, Kondo K, Shinzato T, Kawahata M, Yamaguchi K, et al. Absolute configuration of (+)-pinoresinol 4-O-[6"O-galloyl]- $\beta$-D-glucopyranoside, macarangiosides $\mathrm{E}$, and $\mathrm{F}$ isolated from the leaves of Macaranga tanarius. Phytochemistry 2009;70(10): 1277-85.

17. Puteri MG, Kawabata J. Novel $\alpha$-glucosidase inhibitors from Macaranga tanarius. Food Chem 2010;123:384-9.

18. Janakat S, Al-Merie H. Optimization of the dose and route of injection, and characterisation of the time course of carbon tetrachloride-induced hepatotoxicity in the rat. J Pharmacol Toxicol Methods 2002;48(1):41-4.

19. Panjaitan RGP, Handharyani E, Chairul, Masriani, Zakiah Z, Manalu W. The effects of carbon tetrachloride administration on liver and renal function. Makara Kesehatan 2007;11(1):11-6 (in Indonesian).

20. Gupta M, Mazumder UK, Kumar TS, Gomathu P, Kumar RS. Antioxidant and hepatoprotective effects of Bauhinia racemosa against paracetamol and carbon tetrachloride induced liver damage in rats. Iran J Pharmacol Ther 2004;3(1):12-20.

21. Koyama T, Chounan R, Uemura D, Yamaguchi K, Yazawa K. Hepatoprotective effect of a hot-water extract from the edible thorny oyster Spondylus varius on carbon tetrachloride-induced liver injury in mice. Biosci Biotechnol Biochem 2006;70(3): 729-31.

22. Xu JY, Su YY, Cheng JS, Li SX, Liu R, Li WX, et al. Protective effects of fullerenol on carbon tetrachloride-induced acute hepatotoxicity and nephrotoxicity in rats. Carbon 2010;48:1388-96.

23. Bashandy SA, Al-Wasel SH. Carbon tetrachloride-induced hepatotoxicity and nephrotoxicity in rats: Protective role of Vitamin C. J Pharmacol Toxicol 2011; 6(3):283-92.

24. Nirmala M, Girija K, Lakshman K, Divya T. Hepatoprotective activity of Musa paradisiaca on experimental animal models. Asian Pac J Trop Biomed 2012;2(1):11-15.

25. Arhoghro EM, Ekpo KE, Ibeh GO. Effect of aqueous extract of scent leaf (Ocimum gratissimum) on carbon tetrachloride $\left(\mathrm{CCl}_{4}\right)$ induced liver damage in albino Wistar rats. Afr J Pharm Pharmacol 2009;3(11):562-7.

26. Pushplata C, Yadunath J, Ashish J. Protective effect of ethanol extract of Centaurea behen linn in carbon tetra chloride-induced hepatitis in rats. Int J Pharm Pharm Sci 2014;6(8):197-200.

27. Dehar N, Walia, R, Verma RB, Pandey P. Hepatoprotective activity of Berberis aristata root extract against chemical induced acute hepatotoxicity in rats. Asian J Pharm Clin Res 2013;6 Supp 5:53-6.

28. Ahmed B, Alam T, Varshney M, Khan SA. Hepatoprotective activity of two plants belonging to the apiaceae and the Euphorbiaceae family. J Ethnopharmacol 2002;79(3):313-6. 